\title{
LH analog and dietary isoflavones support ovarian granulosa cell tumor development in a spontaneous mouse model
}

\author{
Ann M Dorward, Kathryn L Shultz and Wesley G Beamer
}

The Jackson Laboratory, 600 Main St., Bar Harbor, Maine 04609, USA

(Requests for offprints should be addressed to A M Dorward; Email: ann.dorward@jax.org)

\begin{abstract}
The reproductive hormone environment is an important influence upon spontaneous ovarian granulosa cell (GC) tumor development in genetically susceptible (SWR $\times S W X J-9$ ) $F 1$ female mice: androgenic support during puberty stimulates tumorigenesis, while exposure to $17 \beta$-estradiol $\left(E_{2}\right)$ suppresses tumor initiation. We sought to determine whether gonadotropic stimulation was sufficient to initiate GC tumors in a grafted model system, and to determine the potential for dietary isoflavones (genistein and daidzein) as alternatives to $E_{2}$ for tumor chemoprevention in vivo. Isolated ovaries from pre-pubertal (SWR $\times S W X J-9)$ F1 females were transferred to the kidney capsule of host mice homozygous for the hypogonadal ( $h p g / h p g)$ and severe combined immunodeficiency (scid/scid) mutations. CB17; HPG-Prkdc ${ }^{\text {scid }}$ Gnrh1 $1^{\text {hpg }} / \mathrm{Bm}$ host mice received either follicle-stimulating hormone $(\mathrm{FSH})$, or a functional analog for $\mathrm{LH}$ human chorionic gonadotropin for 2 consecutive weeks, at which time the ovary grafts were examined for evidence of tumor initiation. $\mathrm{LH}$ analog administration, but not $\mathrm{FSH}$, initiated GC tumorigenesis in the graft system, suggesting that the LH surge at puberty initiates GC tumor development in genetically susceptible female mice. To assess the chemopreventive potential of phytoestrogens, GC tumor frequency was compared between $(S W R \times S W X J-9) F 1$ females reared on an isoflavone-free diet versus a diet supplemented with $125 \mu \mathrm{g} / \mathrm{g}$ each of the isoflavones daidzein and genistein. It was observed that (SWR $\times$ SWXJ-9) F1 females reared on isoflavone-supplemented diet maintained significantly higher GC tumor frequency (22\%) than females reared on isoflavonefree diet $(11 \%)$, and that non-tumor-bearing siblings reared on the isoflavones had significantly increased ovarian weight, indicative of an overall stimulation of the reproductive hormone axis. The stimulation of GC tumorigenesis by isoflavones, which contrasts with the chemopreventive action of $E_{2}(2.5 \mathrm{mg} / \mathrm{kg})$ administration during pubertal maturation, may result from general stimulation of ovarian growth, and the inability of the genistein and daidzein supplements to suppress LH secretion.
\end{abstract}

Endocrine-Related Cancer (2007) 14 369-379

\section{Introduction}

Juvenile-type granulosa cell (GC) tumors of the ovary are classified as sex-cord stromal tumors, representing the second most frequent class of ovarian tumors appearing in girls younger than 20 years of age (Young et al. 1984). GC tumors present immediate endocrinological and reproductive complications in infants, girls, and young women, and a potential lifethreatening situation if tumors have acquired malignant characteristics, yet little is known about the etiology of this pediatric cancer (Kalfa et al. 2005). The low frequency of juvenile-type GC tumor appearance in the general population has motivated researchers to utilize animal models for investigations of the genetic and hormonal stimuli that support GC tumor development. Female mice of the inbred strain SWR/Bm (hereafter written SWR) are genetically susceptible to the onset of juvenile-type ovarian GC tumors at a low population frequency (1-2\%), and pose a unique spontaneous system for these investigations (Beamer et al. 1998a).

The SWR mouse ovarian tumors are initiated during puberty, between 3 and 4 weeks of age, and are macroscopically evident by 6 weeks as solid or cystic 
hemorrhagic masses homogeneously comprising proliferative GCs (Beamer et al. 1985). The tumors secrete estrogen and inhibin, a characteristic common to human juvenile-type GC tumors, and they progress to a malignant carcinoma with metastatic potential, similar to the progression observed in some human cases (Tennent et al. 1990, Gocze et al. 1997). The endocrinological and genetic investigations of SWR mice and related recombinant inbred strains derived from SWR revealed two interesting features: first, manipulation of the reproductive hormone environment with exogenously supplied androgenic substrates in pre-pubertal females can significantly increase GC tumor frequency, from $\sim 2$ to $30 \%$ of the susceptible population developing tumors (Beamer et al. 1988, Tennent et al. 1993). Secondly, spontaneous GC tumor frequency is increased to $\sim 25 \%$ in first generation daughters of the (SWR $\times \mathrm{SWXJ}-9)$ cross that introduced supportive tumor susceptibility alleles on mouse chromosome X (Beamer et al. 1998b, Dorward et al. 2003). Overall, the ability to increase tumor frequency by genetic or hormonal means increased the functionality of this mouse model, providing sufficient experimental power to further investigate the biological factors that are either tumor supportive or chemopreventive, and the opportunity to translate these findings into risk reduction strategies for human patients.

The stimulation of GC tumor frequency in prepubertal SWR mice when treated by a dietary supplement or s.c. capsule of testosterone or dehydroepiandrosterone (DHEA) has been replicated in an grafted model system (Beamer et al. 1993). This system requires grafting the pre-pubertal $(<22$ days) genetically susceptible ovaries under the kidney capsule of doubly homozygous hypogonadal ( $\mathrm{hpg} /$ $h p g$ ) and severe combined-immunodeficient (scid/scid) hosts. The scid/scid mutation prevents graft rejection, since homozygous scid/scid mice lack functional B and T cell surveillance, and the hpg/hpg mutation abrogates gonadotropin release from the pituitary, such that the gonads are not stimulated to produce steroid hormones (Cattanach et al. 1977, Bosma et al. 1983, Mason et al. 1986). The hpg/hpg, scid/scid host animal thus represents a gonadotropin- and gonadal hormone-free system, useful for exogenous hormonal manipulation of the ovary graft environment. Important evidence was revealed by the grafting experiments with regards to both the endocrinological support mechanisms and genetic etiology of this tumor system: 1) without reproductive hormone stimulation of the $\mathrm{hpg} / \mathrm{hpg}$, scid/ scid hosts, no GC tumors were evident in the susceptible ovary grafts, while tumors could be initiated in fertile scid/scid hosts, indicating that normal endocrine stimulation provided by an intact hypothalamic-pituitary axis is both necessary and sufficient for GC tumor development; 2) the GC tumor susceptibility genes function autonomously within the ovary and GCs, as evidenced by tumor initiation in the grafted ovaries when hpg/hpg, scid/ scid hosts were administered testosterone or DHEA; and 3) confirmed the developmental window for tumor susceptibility during puberty, as was previously suggested by the spontaneous GC tumor frequency patterns observed in the tumor-susceptible breeding colonies (Beamer et al. 1985). The ovary transplant experiments suggested that peak spontaneous GC tumor susceptibility was recapitulated when both the ovary and recipient were at the pubertal stage, between 21 and 24 days in the mouse (Beamer et al. 1993). This suggested that events connected to the transition of puberty are highly relevant to GC tumor initiation in this mouse model, within the context of follicular differentiation in the ovary and the onset of gonadotropin cycles that stimulate follicular development. To address the specific role of the pituitary gonadotropins, luteinizing hormone (LH) and follicle-stimulating hormone (FSH), for support of GC tumor initiation, we have utilized the hpg/hpg, scid/scid model to evaluate GC tumor development in ovary grafts following independent stimulation by an LH analog human chorionic gonadotropin (hCG) or FSH administration.

The window for hormonal sensitivity to GC tumor initiation in genetically susceptible female mice suggested that an equivalent window might exist for tumor prevention. It was previously observed that continuous administration of $\mathrm{E}_{2}$ in the diet or by s.c. capsule beginning at 21-22 days of age could significantly reduce GC tumor frequency (Beamer et al. 1988). This tactic for tumor prevention is less than promising, since females are rendered infertile due to negative feedback regulation of continuous high serum $\mathrm{E}_{2}$ on gonadotropin release. We have utilized our highest spontaneous frequency colony, represented by $(\mathrm{SWR} \times \mathrm{SWXJ}-9) \mathrm{F} 1$ females with a population GC tumor frequency of $\sim 25 \%$, as a model to test two experimental strategies to mimic the chemopreventive activity of continuous $\mathrm{E}_{2}$. First, we tested the effect of short-term $\mathrm{E}_{2}$ administration $(2.5 \mathrm{mg} / \mathrm{kg})$ during the developmental window for GC tumor initiation (21-26 days), and secondly, we tested whether dietary isoflavones might provide alternatives for chemoprevention against spontaneous GC tumorigenesis in this mouse model. The isoflavone components of plants, commonly called 'phytoestrogens', are of 
considerable interest to the scientific community for their potential impact on reproductive, cardiovascular, and bone health as a result of their pharmacologic activity to bind and transactivate estrogen receptors (Esrs; Kuiper et al. 1998). Our investigation suggests that $\mathrm{LH}$ is the gonadotropic signal required for GC tumor initiation at puberty in juvenile female mice, and that $\mathrm{E}_{2}$ administered during the window of tumor susceptibility can prevent tumor initiation, likely via suppression of gonadotropin release. Furthermore, in contrast to the generalization that isoflavones have anti-tumor action, we observed that genetically susceptible female mice exposed to the isoflavones, genistein and daidzein, in the diet showed an overall increased frequency of GC tumor initiation, coincident with isoflavone stimulation of ovarian growth.

\section{Materials and methods}

\section{Mice}

All mice were produced and housed in our research colony at The Jackson Laboratory (Bar Harbor, ME, USA) under $14 \mathrm{~h}$ light: $10 \mathrm{~h}$ darkness cycles. Mice were provided with autoclaved NIH-31 diet (6\% fat PMI Nutrition International, Brentwood, MO, USA; unless a custom diet is specified) and $\mathrm{HCl}$-acidified water $(\mathrm{pH} 2.8-3.2)$ ad libitum. Animals were weaned at 20-23 days of age and housed in groups of three to five in $329 \mathrm{~cm}^{2}$ polycarbonate cages containing sterilized white pine shavings. Genetically susceptible female mice were derived from the first filial (F1) generation of SWR inbred females mated to recombinant inbred SWXJ-9 males, and are hereafter described as (SWR $X$ SWXJ-9) F1 females. Double mutant hypogonadal (hpg/hpg) and severe combined immunodeficient (scid/scid) CB17; HPG-Prkdc ${ }^{\text {scid }}$ Gnrhl ${ }^{\text {hpg }} / \mathrm{Bm}$ mice (Jax Stock No. 002038) were derived from breeders homozygous for the scid/scid mutation, but heterozygous for the $h p g /+$ mutation, since homozygous females and males are infertile, lacking both circulating gonadotropins and gonadal hormones as a result of a deletion in the gonadotropin-releasing hormone (Gnrh) gene (Cattanach et al. 1977, Mason et al. 1986). Offspring were genotyped for hpg/hpg homozygosity by PCR, to identify individuals homozygous for the Gnrh gene deletion (wild-type product= $712 \mathrm{bp}$, mutant product $=586 \mathrm{bp}$ ). Genomic DNA isolated from tail tip biopsy $(2 \mu \mathrm{l})$ was added to a $24 \mu \mathrm{l}$ reaction mix: $19.75 \mu \mathrm{l} \mathrm{H}_{2} \mathrm{O}, 2.5 \mu \mathrm{l} 10 \times$ concentrated Clontech Advantage buffer, $0.25 \mu \mathrm{l}$ Clontech Advantage Taq polymerase (BD Bioscience-Clontech), $0.5 \mu \mathrm{l}$ dNTPs $(2.5 \mathrm{mM})$, and
$0.5 \mu \mathrm{l}$ each of primers $\mathrm{A}, \mathrm{B}$, and $\mathrm{C}(10 \mu \mathrm{M})$ : primer $\mathrm{A}$ (5'-CACATCTGTAGCCACAGTCC- $3^{\prime}$ ), primer B (5'-AGCTCCGAGGCTGTCACTGG-3'), and primer C (5'-GCTTGGAGAGCTGTAAGGTC-3'). PCR cycles were as follows: $94{ }^{\circ} \mathrm{C} 1 \mathrm{~min}, 35$ cycles of $94{ }^{\circ} \mathrm{C} 30 \mathrm{~s}$ and $68^{\circ} \mathrm{C} 3 \mathrm{~min}$, followed by $68^{\circ} \mathrm{C} 3$-min final extension phase. In addition to PCR genotyping, male and female host gonads were visually inspected prior to ovary grafting to confirm sexual immaturity and hypogonadism. All animal procedures were approved by the Animal Care and Use Committee of The Jackson Laboratory.

\section{Grafting studies}

Ovary pairs were isolated from pre-pubertal (SWR $\times$ SWXJ-9) F1 (15-20 days) females killed by cervical dislocation. Ovaries were immediately transferred under the left kidney capsule of $h p g / h p g$, scid/scid male or female host recipients anesthetized with 2,2,2tribromoethanol (Sigma-Aldrich Chemical Co.) and gonadotropic or hormonal stimulus simultaneously initiated (Cunliffe-Beamer 1983). The gonadotropins, rat FSH-B1 (15 $\mu \mathrm{g} /$ day), ovine FSH S-18 (3 $\mu \mathrm{g} /$ day; National Institutes of Health (NIH) Pituitary Hormone Program, Bethesda, MD, USA), or hCG (15 IU/day; Wyeth-Ayerst, Madison, NJ, USA), were administered in sterile PBS via s.c. Alzet osmotic pumps (Durect Corp., Cupertino, CA, USA). 1007D Alzet pumps were replaced after 1 week, to achieve 2 weeks of continuous gonadotropin exposure. Following this period, at an ovary graft age of $\sim 5$ weeks, the hosts were killed by cervical dislocation and the grafts fixed in Bouin's solution for histological assessment.

DHEA was administered via s.c. capsule made from a $1 \mathrm{~cm}$ length of silastic tubing (Cat No. 508-009, Fisher Scientific, Pittsburgh, PA, USA), solid packed with DHEA (Sigma-Aldrich Chemical Co.) and plugged with $3 \mathrm{~mm}$ diameter glass beads (Fisher Scientific), as previously reported (Beamer et al. 1988). The ovary grafts remained in the DHEA-treated hosts for 5 weeks before the assessment of GC tumor growth (ovary graft, 8 weeks of age) and fixation of the graft in Bouin's solution for histological examination. In cases where the host diet was modified, the custom diets (see below) were introduced to $h p g / h p g, ~ s c i d / s c i d ~$ hosts 5-7 days prior to ovary grafting.

\section{Short-term exposure to $\mathrm{E}_{\mathbf{2}}$}

To determine whether short-term $\mathrm{E}_{2}$ exposure at puberty was equally effective as continuous $E_{2}$ to prevent GC tumor initiation, we administered an s.c. injection of $E_{2}$ dissolved in $100 \mu \mathrm{l}$ peanut oil vehicle 
$(2.5 \mathrm{mg} / \mathrm{kg} \mathrm{BW})$ at $22 \pm 1$ days of age, and once again 3 days following the first injection. Each litter was divided into one of two treatment arms, and control females from each litter received two injections of the peanut oil vehicle on the same schedule.

\section{Custom rodent diets}

Two isocaloric experimental diets were introduced to female mice genetically susceptible to spontaneous ovarian GC tumors: 1) AIN-76A is a purified rodent diet devoid of isoflavone-containing ingredients, with casein as the major protein source (Harlan Teklad, Madison, WI, USA) and 2) a custom diet formulation based on AIN-76A that we have named AIN-D/G, was supplemented at Harlan Teklad with $125 \mu \mathrm{g} / \mathrm{g}$ each of the isoflavones daidzein and genistein (Indofine Chemical Co., Hillsborough, NJ, USA) for a total of $250 \mu \mathrm{g}$ isoflavone per gram of diet. The SWR female and SWXJ-9 male breeders used to generate tumorsusceptible $(\mathrm{SWR} \times \mathrm{SWXJ}-9) \mathrm{F} 1$ females are usually fed the open formula diet NIH-31 diet with $6 \%$ fat. Historically, this diet supports $25 \%$ spontaneous ovarian GC tumor frequency in the $\mathrm{F} 1$ daughter offspring (Beamer et al. 1998b). When experimental diets were introduced, the SWR and the SWXJ-9 breeders were placed on the experimental diet (AIN$76 \mathrm{~A}$ or $\mathrm{AIN}-\mathrm{D} / \mathrm{G})$ at an early age (4 weeks), such that their daughter offspring would be exposed to the dietary constituents in utero, throughout infancy and puberty, until the time of necropsy and tumor assessment at 8 weeks of age.

\section{Ovarian histology and follicle staging}

A minimum of 12 ovaries from females aged 24 days from both isoflavone-free and isoflavone-supplemented diet groups were fixed with Bouin's fixative, serially sectioned ( $5 \mu \mathrm{m}$ sections) and stained with $\mathrm{H} \& \mathrm{E}$ for follicle staging. Every fifth section was examined for growing follicles that were categorized as primary (one GC layer), secondary (two GC layers), pre-antral (three or more GC layers), or antral (three or more layers plus an antral space), and follicles were counted only if the sections transversed the germinal vesicle, in order to prevent duplicated counts.

\section{Serum assays for FSH and LH}

Mouse serum FSH RIAs and LH sandwich immunoassays were performed at the University of Virginia Center for Research in Reproduction Ligand Assay and Analysis Core (NICHD (SCCPRR) Grant U54HD28934, http://www.healthsystem.virginia.edu/ internet/crr/methodspage.cfm). Serum was collected from coagulated whole-blood samples, and stored at $-20{ }^{\circ} \mathrm{C}$ until dry ice shipment to UVA. Assays were performed in duplicate unless volume was limiting.

\section{Statistical analysis}

$\chi^{2}$ Analysis for proportions was used to evaluate GC tumor frequencies between treated and control groups at a significance level of $P<0.05$. Since it was uncertain what effect the treatments would have on GC tumor frequency, power calculations to determine sufficient sample size were based on ongoing estimates of tumor frequency during the dietary manipulation experiments, with $\alpha=0.05$ and $\beta=0.20$. For measurement of the effect of $E_{2}$ on tumor frequency, the minimum sample size was estimated at 47 individual animals, and for the isoflavone study, the minimum sample size was estimated at 113 individual animals. Follicle stages were calculated as a proportion of the total counted, and means and standard errors of the proportions are presented in the results sections. Statistical analyses were performed on arcsinetransformed proportion data. ANOVA was used to compare the continuous variables of body and organ weights, serum FSH and LH, with a significance level of $P<0.05$ (JMP Statistical Software, Version 6.0; SAS Cary, NC, USA).

\section{Results}

\section{Gonadotropin stimulation of GC tumorigenesis}

The gonadotropic stimulus for spontaneous GC tumor initiation in genetically susceptible $(\mathrm{SWR} \times \mathrm{SWXJ}-9)$ $\mathrm{F} 1$ females was examined in an grafting model system utilizing double mutant hpg/hpg, scid/scid recipients. Table 1 shows the summary of histological observations for grafted pre-pubertal (21-22 days) ovaries when treated for 2 consecutive weeks with hCG or FSH. Both ovine and rat FSH stimulated the growth of ovarian follicles, such that the number of GC cells per follicle was greatly increased in an organized pattern, with most follicles having developed an antrum. In a

Table 1 Response of pre-pubertal (3 weeks; SWR $\times S W X J-9$ ) F1 ovarian grafts to 14 days of continuous gonadotropin exposure

\begin{tabular}{lcccc}
\hline Gonadotropin & $\boldsymbol{n}$ & $\begin{array}{c}\text { Normal } \\
\text { histology }\end{array}$ & $\begin{array}{c}\text { Blood- } \\
\text { filled cyst }\end{array}$ & $\begin{array}{c}\text { Pre-neoplastic } \\
\text { follicles }\end{array}$ \\
\hline Rat FSH & 9 & 7 & 2 & 0 \\
Ovine FSH & 8 & 7 & 1 & 0 \\
HCG & 14 & 3 & 4 & 7 \\
\hline
\end{tabular}


few sections, there was evidence for blood-filled cysts, but there was no evidence for ovarian GC tumors in 17 independently treated grafts (Fig. 1A and B). In contrast, hCG stimulated the development of preneoplastic follicles, with evidence for cystic bloodfilled spaces and irregular proliferative masses of GC cells in 7 out of 14 independent grafts (Fig. 1C and D). This suggests that LH provides the upstream stimulus for GC tumor initiation in cases of spontaneous GC tumor development in $(S W R \times S W X J-9)$ F1 female mice.

In the absence of gonadotropic support, ovary grafts failed to thrive, with no evidence of follicular growth or neoplasia (Fig. 1E and F).

\section{Effect of short-term $E_{2}$ administration}

Short-term administration of $\mathrm{E}_{2}$ was accomplished by two injections of $E_{2}$ in oil vehicle during the pubertal window between 21 and 26 days of age. It was observed that short-term $\mathrm{E}_{2}$ administration during this period significantly reduced GC tumor frequency from $27 \%(13 / 48)$ in the oil vehicle-treated control group to $4 \%(2 / 49)$ in the $\mathrm{E}_{2}$-treated group. Four females treated with $\mathrm{E}_{2}$ were fertility tested at 8 weeks of age to confirm that short-term $E_{2}$ exposure did not affect subsequent reproductive potential. $\mathrm{E}_{2}$-treated females produced litters of equal size and with equivalent latency as females provided with the oil vehicle control (data not shown).
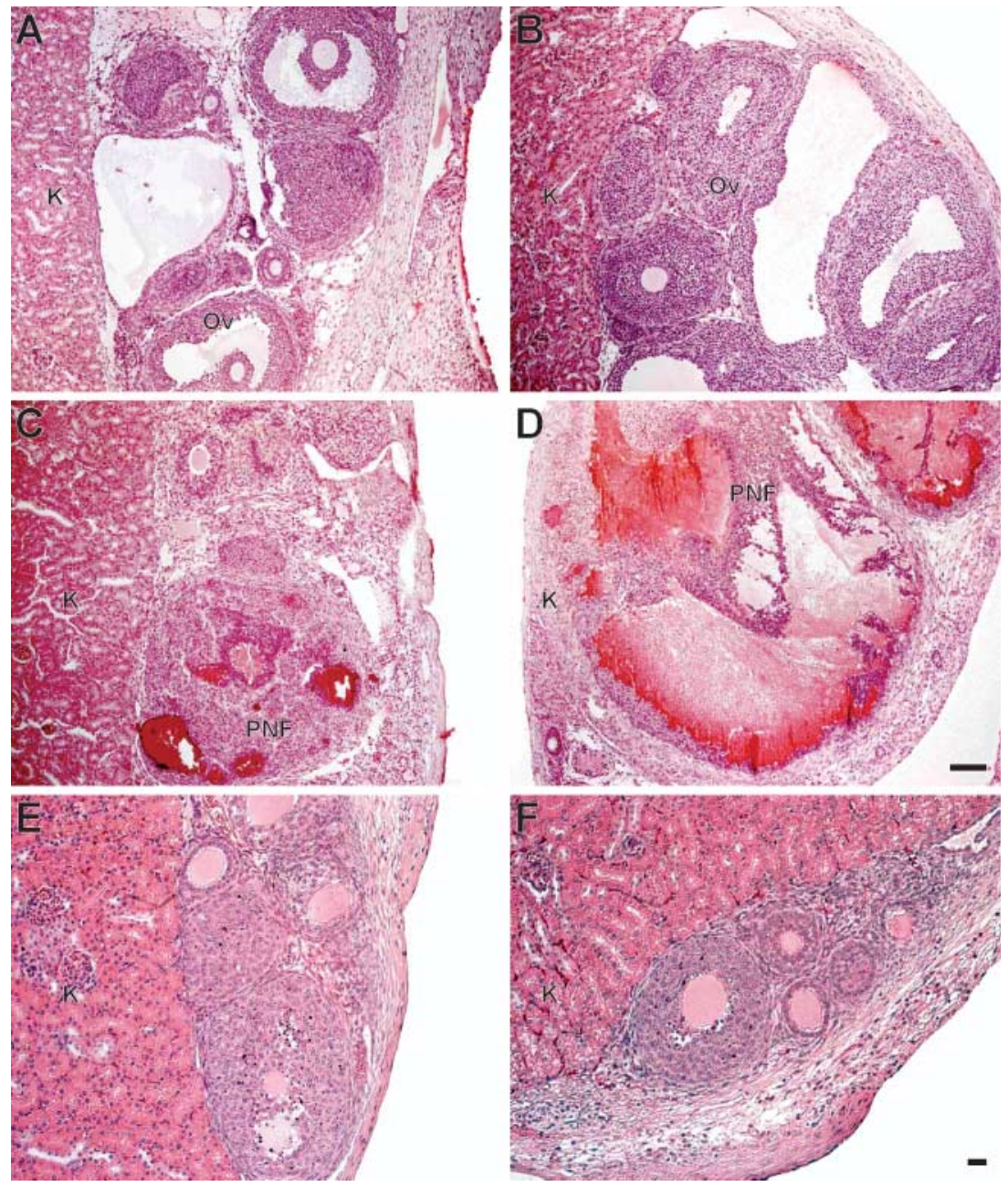

Figure 1 Follicular appearance of (SWR $\times$ SWXJ-9) F1 ovaries (Ov) grafted under the kidney (K) capsule of $h p g / h p g$, scid/scid hosts following 2 weeks of continuous gonadotropin administration. FSH stimulated GC proliferation and the development of antral follicles (A and B). In contrast, hCG-triggered GC tumor initiation, evident as pre-neoplastic foci (PNF) in the ovary grafts, with irregular masses of GCs and blood pooling ( $C$ and $D)$. In the absence of gonadotropic support, ovarian grafts showed no evidence of growth at 10- or 14-day post-engraftment ( $\mathrm{E}$ and $\mathrm{F})$. All tissue sections were stained with hematoxylin/eosin (scale bar $=1 \mathrm{~mm})$. 


\section{Dietary isoflavones and spontaneous GC tumorigenesis}

Reproductive performance of the SWR and SWXJ-9 breeder pairs on the two experimental diets was consistent with breeders maintained on NIH-31 diet, indicating no adverse effects of isoflavone depletion or supplementation to the overall fertility of these animals. Table 2 shows the GC tumor frequencies recorded in the $(\mathrm{SWR} \times \mathrm{SWXJ}-9) \mathrm{F} 1$ females reared on the experimental diets. There was a significant increase in GC tumor frequency in the $(\mathrm{SWR} \times \mathrm{SWXJ}-9) \mathrm{F} 1$ population reared on the AIN-D/G diet $(\sim 22 \%)$ supplemented with isoflavones, when compared with the AIN-76A isoflavone-free diet $(\sim 11 \%)$. Table 2 also summarizes body and organ weight data for female mice necropsied at the age of 8 weeks; these data are sub-categorized by tumor status, whether the females had a GC tumor (unilateral or bilateral), or macroscopically normal ovaries. There were no significant differences in the body weights of females on either diet regardless of tumor-bearing status; since these diets are calorie matched and equally digestible, this suggests no overt changes in food consumption with either diet. Of those females with GC tumors, it was evident that the tumors were larger in females fed the AIN-D/G diet, as shown by the normalized weight of GC tumors. In cases where the tumors were bilateral, the larger tumor was entered into this calculation. In females without GC tumors, the ovary pair weight was also significantly increased in females raised on AIN-D/G versus AIN-76A, suggesting an overall stimulation of ovary growth by the isoflavone supplement. Uterine weights were significantly increased in tumor-bearing animals from either diet group, as has been observed previously, but no differences were observed in females with normal ovaries fed either experimental diet.

The significant increase in ovarian weight measured at 8 weeks for females fed AIN-D/G suggested that the isoflavone supplement of daidzein and genistein supported ovarian growth. We subsequently examined juvenile females at 24 and 30 days of age from the AIN-76 and AIN-D/G diet groups to measure body and organ weight parameters, and serum gonadotropin concentrations at the age of GC tumor initiation. Figure 2A-E shows the body weight, and ovary and uterine weights normalized to body weight, along with the serum FSH and LH concentrations measured in 24and 30-day-old females. The pattern of increased ovarian weight in AIN-D/G- versus AIN-76A-fed females was evident at both 24 and 30 days, indicating that enhanced ovarian growth was established prior to the onset of puberty. No significant differences in serum FSH or LH were observed at 24 or 30 days of age, although the variability was still high within this genetically homogenous population of animals, and despite their being raised in a controlled environment on a uniform diet. The significant increase in ovarian and uterine weight observed at 24 days of age in AIN-D/G-reared mice suggested puberty acceleration, which could be an outcome of isoflavone supplementation. Follicle staging of 24-day-old ovaries obtained from both diet groups did reveal an increased proportion of large pre-antral follicles in animals receiving the isoflavone supplement, with a concomitant reduction in the proportion of follicles at the primary stage (Table 3 ). In addition, several instances of multi-oocyte follicles were observed in ovary sections of isoflavone-supplemented females, but not the isoflavone-free group (data not shown).

The overall reduction in spontaneous GC tumor frequency observed in $(S W R \times S W X J-9) \mathrm{F} 1$ females raised on AIN-76A suggested a diet lacking in isoflavones reduced GC tumor susceptibility. To address whether this 'protection' carried over as permanent defense against a tumor-promotive substance, and whether the dietary isoflavone content of AIN-D/G was independently capable of supporting GC tumor initiation, we utilized the hpg/hpg, scid/scid

Table 2 Body and organ weight measurements for 8-week-old (SWR $\times$ SWXJ-9) F1 females reared on AIN-76A or AIN-D/G diet (mean \pm S.E.M.)

\begin{tabular}{lcllcrr}
\hline Base diet & $\begin{array}{c}\text { GC tumor } \\
\text { frequency }\end{array}$ & Tumor status & $\begin{array}{c}\text { Body weight, } \\
\text { BW }(\mathrm{g})\end{array}$ & $\begin{array}{c}\text { GC tumor } \\
\text { weight/BW } \\
(\mathrm{mg} / \mathrm{g})\end{array}$ & $\begin{array}{c}\text { Ovary pair } \\
\text { weight/BW } \\
(\mathrm{mg} / \mathrm{g})\end{array}$ & $\begin{array}{c}\text { Uterine } \\
\text { weight/BW } \\
(\mathrm{mg} / \mathrm{g})\end{array}$ \\
\hline AIN-76A & $30 / 273(10.9 \%)$ & Normal $(n=130)$ & $18.27 \pm 0.15$ & - & $0.37 \pm 0.01$ & $4.31 \pm 0.12$ \\
& & Tumor bearing $(n=18)$ & $18.68 \pm 0.34$ & $4.75 \pm 1.19$ & - & $6.76 \pm 0.45^{\star}$ \\
AIN-D/G & $23 / 105^{\dagger}(21.9 \%)$ & Normal $(n=82)$ & $18.53 \pm 0.15$ & - & $0.43 \pm 0.01^{\dagger}$ & $4.65 \pm 0.17$ \\
& & Tumor bearing $(n=23)$ & $19.17 \pm 0.25$ & $24.89 \pm 4.36^{\dagger}$ & - & $7.47 \pm 0.18^{\ddagger}$ \\
\hline
\end{tabular}

${ }^{*}$ Significant difference $(P<0.05)$ between tumor- and non-tumor-bearing animals in the AIN-76A-fed group. ${ }^{\dagger}$ Significant difference $(P<0.05)$ between the diet groups for similar measurement under similar tumor-bearing condition. ${ }^{\ddagger}$ Significant difference $(P<0.05)$ between tumor- and non-tumor-bearing animals in the AIN-D/G group. 


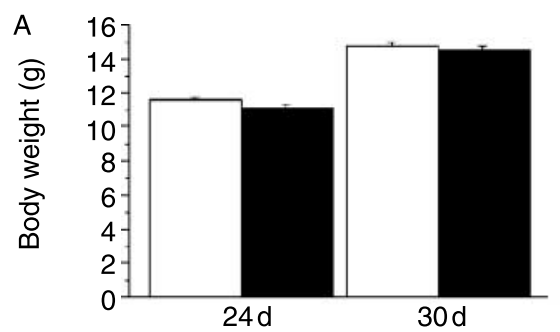

AIN-76A

AIN-DG
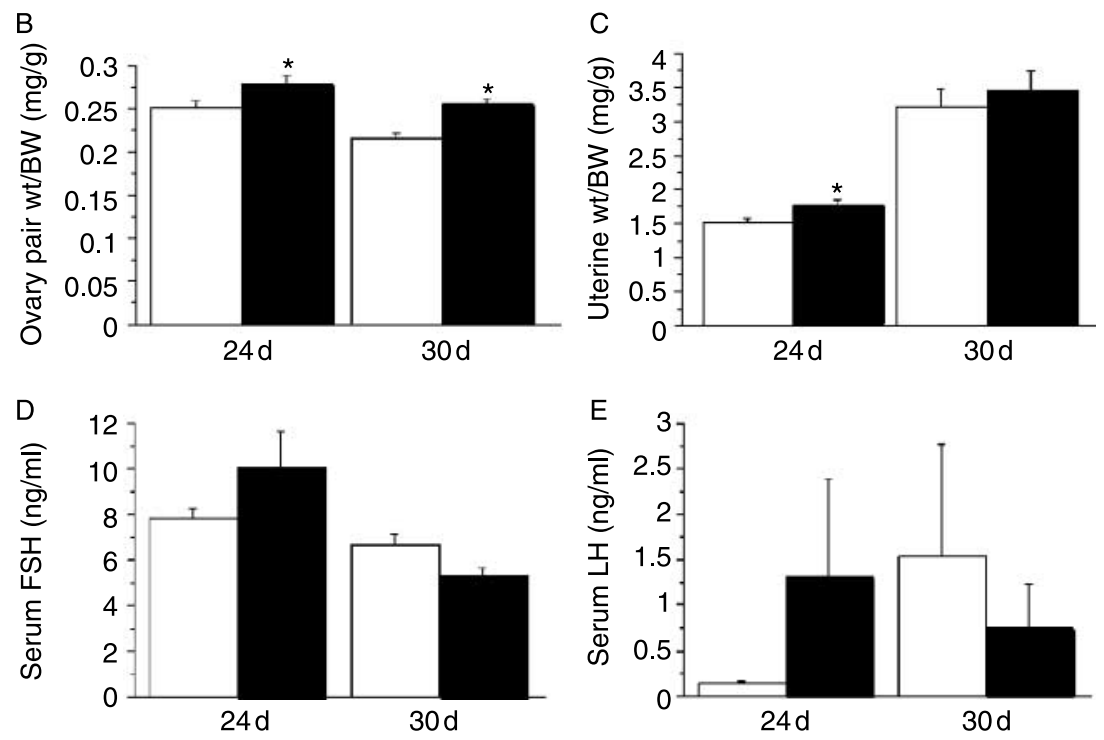

Figure 2 Mean \pm S.E.M. for body, organ weights, and serum gonadotropins of pubertal (SWR $\times$ SWXJ-9) F1 females raised on an isoflavone-free (AIN-76A) diet or a supplemented (AIN-D/G) diet containing the isoflavones genistein $(125 \mu \mathrm{g} / \mathrm{g})$ and daidzein $(125 \mu \mathrm{g} / \mathrm{g})$. Minimum group size $n=45$ for $(\mathrm{A})$ body weight $(\mathrm{BW}),(\mathrm{B})$ ovary weight/BW, and $(\mathrm{C})$ uterine weight/BW measurements. For serum FSH (D), minimum group size $n=18$, and for serum LH $(\mathrm{E}), n=20$. Significant differences $(P<0.05)$ determined by ANOVA are indicated by *.

graft model. Table 4 shows that GC tumor frequency could be stimulated to $27 \%$ when an s.c. DHEA capsule was simultaneously inserted at the time of ovary grafting, this suggests that AIN-76A feeding does not prevent GC tumor initiation in the presence of exogenous androgenic tumor support, and reduction of spontaneous GC tumor frequency observed in the group reared on AIN-76A may result from the immediate changes in endocrine environment. When hpg/hpg, scid/scid hosts were fed AIN-76A or AIN-D/ $\mathrm{G}$, and received ovary grafts from the colonies maintained on AIN-76A or AIN-D/G, no GC tumors were evident, indicating that the isoflavone supplement present in the AIN-D/G diet did not independently support GC tumor initiation (Table 4).

\section{Discussion}

Juvenile SWR female mice are genetically susceptible to the development of spontaneous ovarian GC tumors between 3 and 4 weeks of age when the ovary and hypothalamic-pituitary axis undergo reproductive maturation. Genetic susceptibility is inherent within the GCs of the SWR ovary, and tumor initiation requires endocrine support provided by the intact hypothalamic-pituitary axis. We have grafted

Table 3 Follicle growth in (SWR $\times$ SWXJ-9) F1 female ovaries at 24 days: influence of isoflavone-supplemented diet

\begin{tabular}{lcccc}
\hline Diet & Primary & Secondary & Pre-antral & Antral \\
\hline AIN-76A & $0.389 \pm 0.017$ & $0.303 \pm 0.014$ & $0.134 \pm 0.016$ & $0.171 \pm 0.011$ \\
AIN-D/G & $0.317^{\star} \pm 0.015$ & $0.291 \pm 0.012$ & $0.224^{*} \pm 0.014$ & $0.169 \pm 0.009$ \\
\hline
\end{tabular}

*Significant difference $(P<0.05)$ between AIN-76A and AIN-D/G groups. 
Table 4 GC tumor frequency in 8-week-old (SWR $\times$ SWXJ-9) F1 ovary grafts transferred to $h p g / h p g$, scid/scid hosts at 3 weeks: a comparison of isoflavone-free or supplemented diet effects for tumor prevention or promotion

\begin{tabular}{lllr}
\hline $\begin{array}{l}\text { Ovary graft } \\
\text { source diet }\end{array}$ & $\begin{array}{l}\text { hpg/hpg, } \\
\text { scid/scid } \\
\text { host diet }\end{array}$ & $\begin{array}{l}\text { Capsule } \\
\text { implant }\end{array}$ & $\begin{array}{r}\text { GC tumor } \\
\text { frequency }\end{array}$ \\
\hline AIN-76A & AIN-76A & Empty & $0 / 35(0 \%)$ \\
AIN-76A & AIN-76A & DHEA & $9 / 33(27 \%)$ \\
AIN-76A & AIN-D/G & Empty & $0 / 21(0 \%)$ \\
AIN-D/G & AIN-D/G & Empty & $0 / 25(0 \%)$ \\
\hline
\end{tabular}

genetically susceptible ovaries into immunodeficient, hypogonadal recipient mice in order to determine which gonadotropic stimulus - LH or FSH - supports GC tumor initiation. The observation that the LH analog hCG stimulates pre-neoplastic follicle development in ovary grafts, while FSH stimulates only follicle growth, suggests that LH is the tumor initiation stimulus during pubertal maturation of the juvenile animal. This observation is consistent with the fact that androgenic steroids, downstream products of LH-stimulated thecal cells, are also capable of stimulating GC tumor initiation in the graft system (Beamer et al. 1993). Continuous LH stimulation has been associated with various conditions of ovarian pathology in several transgenic and gene knockout models, including the development of cystic, hemorrhagic follicles, or sex-cord stromal tumors (Matzuk et al. 1992, Risma et al. 1995, Couse et al. 1999, Britt et al. 2000, Danilovich et al. 2001). However, these genetically engineered mouse models contrast strikingly with the SWR model system, since they pose adult-onset pathology resulting from chronic, elevated gonadotropic stimulation, which is not required for juvenile-onset GC tumorigenesis in SWR female mice. To date, no association has developed between mutations in the gonadotropins, gonadotropin receptor, or inhibin genes and juvenile GC tumor development in children, nor do these genes overlap with the known tumor susceptibility loci identified in SWR mice (Shen et al. 1996, Watson et al. 1997, Beamer et al. 1998b, Fuller et al. 1998, Dorward et al. 2005). Thus, the pursuit of the tumor susceptibility genes operative in the SWR spontaneous mutant strain will provide novel candidates for investigation of both the genetic determinants and the endocrinological interactions that support human cases of juvenile-onset GC tumorigenesis.

An inherent property of GC tumor development in SWR female mice is the restricted window for GC tumor susceptibility during puberty. This window of susceptibility is emphasized under conditions of androgenic exposure, which stimulates tumor frequency in pre-pubertal females, but not in females aged beyond the susceptibility window. This investigation has now confirmed that successful chemoprevention by $E_{2}$ overlaps the period of GC tumor initiation. The tumor-preventive action of continuous exposure to elevated $E_{2}$ initiated prior to puberty is recapitulated by short-term $\mathrm{E}_{2}$ exposure during the pubertal maturation window. Building on the evidence for LH-triggered GC tumor initiation, we now propose that the mechanism of action for high-dose $E_{2}$ chemoprevention is to suppress gonadotropins, and more specifically $\mathrm{LH}$ release from the anterior pituitary, thus delaying gonadotropic cyclicity until the window for tumor susceptibility is passed.

As an alternative to $E_{2}$, we also examined the chemopreventive potential of dietary isoflavones on GC tumor frequency in genetically susceptible mice. Generally, the term 'phytoestrogen' is applied to plantderived isoflavones, lignans and coumestans, that have weak estrogenic activity in vivo and in vitro, via binding and transactivation of (Esr1 and Esr2) receptors, as well as non-hormonal activities, such as inhibition of tyrosine kinases (Akiyama et al. 1987, Kuiper et al. 1998). Our study took into account data that commercially available rodent chows, including the NIH-31 chow utilized by The Jackson Laboratory, contain significant amounts of isoflavones contributed by soy and alfalfa ingredients (Thigpen et al. 1999). We therefore compared GC tumor frequency and reproductive status between tumor-susceptible females reared on a commercially available isoflavone-free synthetic diet (AIN-76A), versus the same diet supplemented with a 1:1 combination of genistein and daidzein, to emulate the major constituents and peak concentration in the NIH-31 diet. In contrast to $\mathrm{E}_{2}$ administration, a total dietary isoflavone supplement of $250 \mu \mathrm{g} / \mathrm{g}$ did not prevent GC tumor development; rather, our study provided consistent evidence that isoflavones supported GC tumor initiation in this spontaneous tumor model. First, GC tumor frequency dropped significantly in females reared on the isoflavone-free diet, where $11 \%$ were tumor-bearing relative to the expected frequency of $\sim 25 \%$ on the isoflavone-containing NIH-31 diet. Secondly, GC tumor frequency rebounded significantly from 11 to $22 \%$ when isoflavones were reintroduced to the maternal diet, and genetically susceptible female offspring were exposed in utero, during lactation, puberty, and young adulthood. The inability of isoflavones to prevent GC tumor initiation could be explained by the fact that gonadotropin levels were not 
reduced by the dietary isoflavone supplementation during the critical window for tumor initiation. This finding agrees with the genetic evidence that signaling via the Esr1 receptor is most important for negative feedback regulation of gonadotropin release, while pharmacological data show that the isoflavones genistein and daidzein show preferential binding and transactivation of the Esr2 receptor subtype (Kuiper et al. 1998, Couse et al. 2003).

The ability of isoflavones to support GC tumor development in this animal model raises the question as to their mechanism of action. The genistein- and daidzein-supplemented diet did not support GC tumor initiation in genetically susceptible ovaries grafted into $h p g / h p g$, scid/scid recipients, suggesting that the isoflavones cannot stimulate GC tumor initiation independently from gonadotropic stimulation. The supportive action of the isoflavones for GC tumor initiation may be a function of their Esr2 receptor subtype specificity, acting via transactivation of Esr2 to support GC differentiation and follicular development in vivo (Sar \& Welsch 1999, Hegele-Hartung et al. 2004, Couse et al. 2005, Emmen et al. 2005). The isoflavone combination of genistein and daidzein did increase the proportion of large growing follicles in genetically susceptible female mice, which may effectively render a larger population of GCs responsive to the genetically programmed tumorigenic events. Multi-oocyte follicles were also observed in juvenile ovaries from isoflavone-supplemented females, as previously reported following neonatal exposure to genistein (Jefferson et al. 2006). Although the mechanism of action is not yet fully elucidated, the finding for a tumor-supportive interaction between juvenile GC tumor susceptibility genes and isoflavones in female mice is disturbing. Pediatric GC tumors may arise during infancy and isoflavones can be measured in the amniotic fluid of pregnant mothers consuming soy products (Engel et al. 2006). Furthermore, infants fed soy-based formula are exposed to high concentrations of genistein and daidzein, in excess of 13000 times the normal concentration of plasma $E_{2}$ equivalents (Setchell et al. 1997).

Tumor susceptibility genes associated with human juvenile- and adult-onset GC tumors have not yet been identified, although multiple mouse models that develop late-onset GC tumors have been engineered through transgenic overexpression of LH, and knockouts for the FSH receptor $(F s h r)$ and inhibin $\alpha$ (Inha) genes (Matzuk et al. 1992, Risma et al. 1995, Danilovich et al. 2001). GC tumor susceptibility in mice that overexpress LH is influenced by the genetic background of the transgenic strain, with at least three genes predicted to modify tumor susceptibility (Keri et al. 2000). The SWR mouse model for spontaneous juvenile-type GC tumor development shares common elements with the genetically engineered models, since tumor initiation can be triggered by $\mathrm{LH}$ and tumor susceptibility is a polygenic trait. The downstream effector of $\mathrm{LH}$ seems to be androgenic stimulation in SWR ovary, as both testosterone and DHEA can stimulate tumor development in a grafted, genetically susceptible ovary without gonadotropic influence (Beamer et al. 1993). One major difference between the spontaneous tumors that arise in inbred SWR mice and other genetically engineered models is the narrow developmental window for GC tumor susceptibility during puberty, and the heightened level of sensitivity to initiating factors such as LH or androgens at normal physiological levels. Identification of the genetic alleles that support GC tumor development in SWR mice will be very informative, to compare with the biological pathways that are sufficient to support GC tumorigenesis in engineered model systems, such as dysregulation of Wnt and $\beta$-catenin tumor suppressor genes (Boerboom et al. 2005, 2006). In addition, successful positional cloning efforts in SWR mice to identify the relevant ovarian tumor susceptibility genes will open up a more detailed investigation as to the mechanism by which specific isoflavones contribute to GC tumor initiation in the ovary.

\section{Acknowledgements}

We would like to thank Dr Barb Mickelson at Harlan Teklad for informative discussions, and Dr Clifford Rosen, Dr Leah Rae Donahue and Krista Delahunty for their helpful comments on this manuscript.

\section{Funding}

Cancer Research Foundation of America Fellowship (AMD), an anonymous foundation (AMD), American Institute for Cancer Research grant (01B094) (WGB), National Institutes of Health AR43618 (WGB, KLS), National Cancer Institute Cancer Core grant (CA34196) to The Jackson Laboratory. University of Virginia Center for Research in Reproduction-Ligand Assay and Analysis Core (NICHD (SCCPRR) Grant U54-HD28934). There is no conflict of interest between the authors and the funding agencies that would prejudice the impartiality of this work. 


\section{References}

Akiyama T, Ishida J, Nakagawa S, Ogawara H, Watanabe S, Itoh N, Shibuya M \& Fukami Y 1987 Genistein, a specific inhibitor of tyrosine-specific protein kinases. Journal of Biological Chemistry $2625592-5595$.

Beamer WG, Hoppe PC \& Whitten WK 1985 Spontaneous malignant granulosa cell tumors in ovaries of young $S W R$ mice. Cancer Research 45 5575-5581.

Beamer WG, Shultz KL \& Tennent BJ 1988 Induction of ovarian granulosa cell tumors in $S W X J-9$ mice with dehydroepiandrosterone. Cancer Research 48 2788-2792.

Beamer WG, Shultz KL, Tennent BJ \& Shultz LD 1993 Granulosa cell tumorigenesis in genetically hypogonadalimmunodeficient mice grafted with ovaries from tumorsusceptible donors. Cancer Research 53 3741-3746.

Beamer WG, Shultz KL, Tennent BJ, Azumi N \& Sundberg JP $1998 a$ Mouse model for malignant juvenile ovarian granulosa cell tumors. Toxicologic Pathology 26 704-710.

Beamer WG, Shultz KL, Tennent BJ, Nadeau JH, Churchill GA \& Eicher EM 1998b Multigenic and imprinting control of ovarian granulosa cell tumorigenesis in mice. Cancer Research 58 3694-3699.

Boerboom D, Paquet M, Hsieh M, Liu J, Jamin SP, Behringer RR, Sirois J, Taketo MM \& Richards JS 2005 Misregulated Wnt/beta-catenin signaling leads to ovarian granulosa cell tumor development. Cancer Research $\mathbf{6 5}$ 9206-9215.

Boerboom D, White LD, Dalle S, Courty J \& Richards JS 2006 Dominant-stable beta-catenin expression causes cell fate alterations and Wnt signaling antagonist expression in a murine granulosa cell tumor model. Cancer Research 66 1964-1973.

Bosma GC, Custer RP \& Bosma MJ 1983 A severe combined immunodeficiency mutation in the mouse. Nature $\mathbf{3 0 1}$ 527-530.

Britt KL, Drummond AE, Cox VA, Dyson M, Wreford NG, Jones ME, Simpson ER \& Findlay JK 2000 An agerelated ovarian phenotype in mice with targeted disruption of the Cyp 19 (aromatase) gene. Endocrinology 141 2614-2623.

Cattanach BM, Iddon CA, Charlton HM, Chiappa SA \& Fink G 1977 Gonadotrophin-releasing hormone deficiency in a mutant mouse with hypogonadism. Nature 269 338-340.

Couse JF, Bunch DO, Lindzey J, Schomberg DW \& Korach KS 1999 Prevention of the polycystic ovarian phenotype and characterization of ovulatory capacity in the estrogen receptor-alpha knockout mouse. Endocrinology 140 5855-5865.

Couse JF, Yates MM, Walker VR \& Korach KS 2003 Characterization of the hypothalamic-pituitary-gonadal axis in estrogen receptor (ER) Null mice reveals hypergonadism and endocrine sex reversal in females lacking ERalpha but not ERbeta. Molecular Endocrinology 17 1039-1053.
Couse JF, Yates MM, Deroo BJ \& Korach KS 2005 Estrogen receptor-beta is critical to granulosa cell differentiation and the ovulatory response to gonadotropins. Endocrinology 146 3247-3262.

Cunliffe-Beamer T 1983 Biomethodology and surgical techniques. In The Mouse in Biomedical Research, pp 402-437. Eds H Foster, J Small \& J Fox. New York: Academic Press.

Danilovich N, Roy I \& Sairam MR 2001 Ovarian pathology and high incidence of sex cord tumors in follitropin receptor knockout (FORKO) mice. Endocrinology 142 3673-3684.

Dorward AM, Shultz KL, Ackert-Bicknell CL, Eicher EM \& Beamer WG 2003 High-resolution genetic map of $\mathrm{X}$-linked juvenile-type granulosa cell tumor susceptibility genes in mouse. Cancer Research 63 8197-8202.

Dorward AM, Shultz KL, Horton LG, Li R, Churchill GA \& Beamer WG 2005 Distal Chr 4 harbors a genetic locus (Gct1) fundamental for spontaneous ovarian granulosa cell tumorigenesis in a mouse model. Cancer Research 65 1259-1264.

Emmen JM, Couse JF, Elmore SA, Yates MM, Kissling GE \& Korach KS 2005 In vitro growth and ovulation of follicles from ovaries of estrogen receptor (ER) $\alpha$ and $\mathrm{ER} \beta$ null mice indicate a role for ER $\beta$ in follicular maturation. Endocrinology 146 2817-2826.

Engel SM, Levy B, Liu Z, Kaplan D \& Wolff MS 2006 Xenobiotic phenols in early pregnancy amniotic fluid. Reproductive Toxicology 21 110-112.

Fuller PJ, Verity K, Shen Y, Mamers P, Jobling T \& Burger HG 1998 No evidence of a role for mutations or polymorphisms of the follicle-stimulating hormone receptor in ovarian granulosa cell tumors. Journal of Clinical Endocrinology and Metabolism 83 274-279.

Gocze PM, Beamer WG, de Jong FH \& Freeman DA 1997 Hormone synthesis and responsiveness of spontaneous granulosa cell tumors in $(\mathrm{SWR} \times \mathrm{SWXJ}-9) \mathrm{F} 1$ mice. Gynecologic Oncology 65 143-148.

Hegele-Hartung C, Siebel P, Peters O, Kosemund D, Muller G, Hillisch A, Walter A, Kraetzschmar J \& Fritzemeier KH 2004 Impact of isotype-selective estrogen receptor agonists on ovarian function. PNAS 101 5129-5134.

Jefferson W, Newbold R, Padilla-Banks E \& Pepling M 2006 Neonatal genistein treatment alters ovarian differentiation in the mouse: inhibition of oocyte nest breakdown and increased oocyte survival. Biology of Reproduction 74 161-168.

Kalfa N, Patte C, Orbach D, Lecointre C, Pienkowski C, Philippe F, Thibault E, Plantaz D, Brauner R, Rubie H et al. 2005 A nationwide study of granulosa cell tumors in pre- and post-pubertal girls: missed diagnosis of endocrine manifestations worsens prognosis. Journal of Pediatric Endocrinology and Metabolism 18 25-31.

Keri RA, Lozada KL, Abdul-Karim FW, Nadeau JH \& Nilson JH 2000 Luteinizing hormone induction of ovarian tumors: oligogenic differences between mouse strains dictates tumor disposition. PNAS 97 383-387. 
Kuiper GG, Lemmen JG, Carlsson B, Corton JC, Safe SH, van der Saag PT, van der Burg B \& Gustafsson JA 1998 Interaction of estrogenic chemicals and phytoestrogens with estrogen receptor beta. Endocrinology 139 4252-4263.

Mason AJ, Hayflick JS, Zoeller RT, Young WS III, Phillips HS, Nikolics K \& Seeburg PH 1986 A deletion truncating the gonadotropin-releasing hormone gene is responsible for hypogonadism in the hpg mouse. Science 234 1366-1371.

Matzuk MM, Finegold MJ, Su JG, Hsueh AJ \& Bradley A 1992 Alpha-inhibin is a tumour-suppressor gene with gonadal specificity in mice. Nature 360 313-319.

Risma KA, Clay CM, Nett TM, Wagner T, Yun J \& Nilson JH 1995 Targeted overexpression of luteinizing hormone in transgenic mice leads to infertility, polycystic ovaries, and ovarian tumors. PNAS 92 1322-1326.

Sar M \& Welsch F 1999 Differential expression of estrogen receptor-beta and estrogen receptor-alpha in the rat ovary. Endocrinology 140 963-971.

Setchell KD, Zimmer-Nechemias L, Cai J \& Heubi JE 1997 Exposure of infants to phyto-oestrogens from soy-based infant formula. Lancet 350 23-27.

Shen Y, Mamers P, Jobling T, Burger HG \& Fuller PJ 1996 Absence of the previously reported $\mathrm{G}$ protein oncogene (gip2) in ovarian granulosa cell tumors. Journal of Clinical Endocrinology and Metabolism 81 4159-4161.

Tennent BJ, Shultz KL, Sundberg JP \& Beamer WG 1990 Ovarian granulosa cell tumorigenesis in SWR-derived F1 hybrid mice: preneoplastic follicular abnormality and malignant disease progression. American Journal of Obstetrics and Gynecology 163 625-634.

Tennent BJ, Shultz KL \& Beamer WG 1993 Genetic susceptibility for $\mathrm{C} 19$ androgen induction of ovarian granulosa cell tumorigenesis in SWXJ strains of mice. Cancer Research 53 1059-1063.

Thigpen JE, Setchell KD, Ahlmark KB, Locklear J, Spahr T, Caviness GF, Goelz MF, Haseman JK, Newbold RR \& Forsythe DB 1999 Phytoestrogen content of purified, open- and closed-formula laboratory animal diets. Laboratory Animal Science 49 530-536.

Watson RH, Roy WJ Jr, Davis M, Hitchcock A \& Campbell IG 1997 Loss of heterozygosity at the alpha-inhibin locus on chromosome $2 \mathrm{q}$ is not a feature of human granulosa cell tumors. Gynecologic Oncology 65 387-390.

Young RH, Dickersin GR \& Scully RE 1984 Juvenile granulosa cell tumor of the ovary. A clinicopathological analysis of 125 cases. American Journal of Surgical Pathology 8 575-596. 